\title{
Cutaneous presentation of COVID-19, Case Report
}

Mahmoud Khalifa Marzouq ${ }^{1}$, Ahmed Mahmoud Khalifa ${ }^{2}$, Osama Mahmoud Khalifa ${ }^{3}$ and Khadiga Ahmed Ismail,5

${ }^{1}$ Consultant of Dermatology and Venereology, King Faisal specialized Hospital, Saudi Arabia.

${ }^{2}$ Department of Forensic and Toxicology, Ain-Shams University, Egypt.

${ }^{3}$ Faculty of Medicine, Ain-Shams University, Egypt.

${ }^{4}$ Clinical Laboratory Department, College of Applied Medical Sciences, Taif University, Saudi Arabia.

${ }_{5}^{5}$ Department of Medical Parasitology, Faculty of Medicine, Ain Shams University, Cairo, Egypt.

* Corresponding Author: Khadiga Ahmed Ismail, Clinical Laboratory Department, College of Applied Medical Sciences, Taif University, Saudi Arabia. Department of Medical Parasitology, Faculty of Medicine, Ain Shams University, Cairo, Egypt

Received date: September 01, 2020; Accepted date: September 26, 2020; Published date: 0ctober 06, 2020

Citation: Caggiula A, Di Loreto M, Pettinicchio M, Vendrame A, Casu C. (2020) Central Giant Cell Granuloma: A Narrative Review Of Radiological Features And Differential Diagnosis. General medicine and Clinical Practice. 3(3) DOI: 10.31579/2639-4162/041

Copyright: (C2020 Khadiga Ahmed Ismail. This is an open-access article distributed under the terms of the Creative Commons Attribution License, which permits unrestricted use, distribution, and reproduction in any medium, provided the original author and source are credited.

\begin{abstract}
COVID-19 has high transmissibility and infectivity among human. On January 30, 2020, the World Health Organization (WHO) in an effort to slow down the global spread of the virus declared the outbreak, "A global public health emergency of international concern". The skin manifestations of the novel coronavirus COVID-19 were not recognized at the early stages of the pandemic but have received much recent attention in scientific journals. Reported manifestations range from pseudo-chilblains to a morbilliform (measles-like) exanthem, urticaria, vesicular eruptions, a dengue-like petechial rash and ovate scaling macules, and plaques mimicking pityriasis rosea.
\end{abstract}

Keywords: COVID-19; coronavirus; skin manifestations

\section{Case Report}

Female patient, 30 years old, presented to the Emergency Department with fever, dry cough, and dyspnea. She gave a history of contact with COVID-19 positive case, she developed maculopapular and vesicular lesions on both hands and feet, some lesions were blackish in color on the third day of admission to the hospital.

\section{On Examination}

She was febrile, her temperature was $38.8^{\circ} \mathrm{C}$, her blood pressure was $100 / 70 \mathrm{mmHg}$ with a heart rate of 90 beats/minute, respiratory rate of 27 breaths/minute, and oxygen saturation of $84 \%$ in room temperature air. She had maculopapular and vesicular lesions on both hands and feet, some lesions were blackish in color, as shown in figures $1 \& 2$.

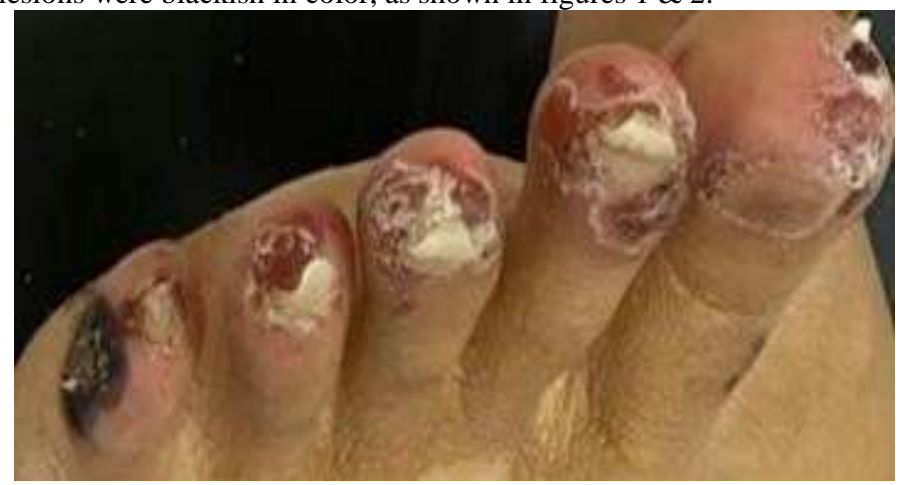

Figure 1: Multiple ulcers with Chilblains like lesions in the toes of left foot, and gangrenous like lesions in the big and little toes

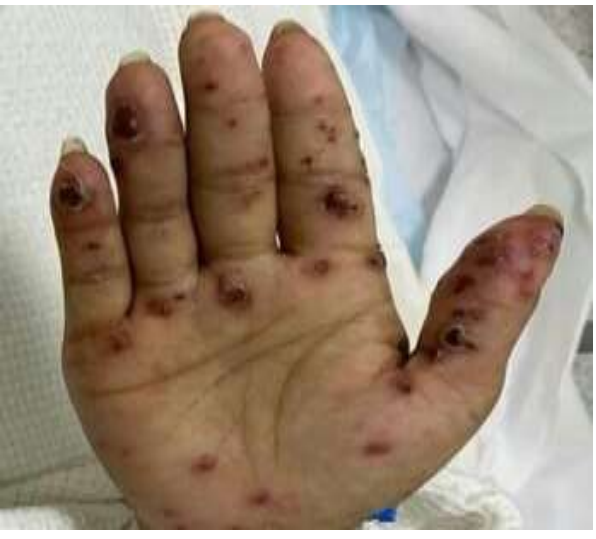

Figure 2: Papulovesicular lesions with inflammation in the palm.

\section{Laboratory Investigations}

As regards her complete blood count:White blood cell count (WBC) of $3.5710^{3} / \mu \mathrm{L}(\mathrm{L})$ (Reference Range:4-11 $10^{3} / \mu \mathrm{L}$ ), with a mild leucopenia, mild relative monocytosis, and moderate absolute lymphopenia. Red blood cell count (RBC) of $3.3610^{6} / \mu \mathrm{L}$ (L) (ReferenceRange: 3.8-5.4 $10^{6} / \mu \mathrm{L}$ ) with a hemoglobin of $10.9 \mathrm{gm} / \mathrm{dL}(\mathrm{L})$ (Reference Range: 11.5$16 \mathrm{gm} / \mathrm{dL}$ ), hematocrit of $32.4 \%$ (L) (Reference Range: $40-50 \%$ ). Platelet count of $10610^{3} / \mu \mathrm{L}(\mathrm{L})$ (Reference Range:150-450 103/ $\mathrm{LL}$ ).

\section{As regards her chemistry:}

Her random glucose of $70 \mathrm{mg} / \mathrm{dL}$ (N) (Reference Range: 70-140mg/dL), blood urea of $20.60 \mathrm{mq} / \mathrm{dL}$ (N) (Reference Range: $20-48 \mathrm{mq} / \mathrm{dL}$ ), 
creatinine of $1.99 \mathrm{mq} / \mathrm{dL}(\mathrm{H})$ (Reference Range: $0.6-1.2 \mathrm{mq} / \mathrm{dL}$ ), $\operatorname{SGOT}(A S T)(30 \mu / L)(N)(n-42 \mu / L), \operatorname{SGPT}(A L T)(14 \mu / L)(N)$

(Reference Range: 0-33 $\mu / \mathrm{L}$ ).

\section{As regards her coagulation profile:}

Partial thromboplastin time (PTT) was (89.4 sec.) (H) (Reference Range: 26-40 seconds), Thromboplastin time (PT) of (16.60 sec.) (H) (Reference Range: 11-14.5 seconds), and INR of $1.30 \%$ (H) (Reference Range 0.8$1.2 \%)$.

RT-PCR positive for COVID-19

\section{Discussion}

Coronaviruses belong to the family Coronaviradae, order Nidovirales, and can be further subdivided into four main genera (Alpha-, Beta-

, Gamma-, and Delta-coronaviruses). Several Alpha- and Betacoronaviruses cause mild respiratory infections and common cold symptoms in humans, whereas others are zoonotic and infect birds, pigs, bats, and other animals. In addition to COVID-19, two other coronaviruses, SARS-CoV and MERS-CoV, caused large disease outbreaks that had high lethality rates $(10 \%-30 \%)$ and widespread societal impact upon emergence [1].

Currently in December 2019, a new infectious respiratory disease emerged in Wuhan, China that caused a severe respiratory illness which is now termed coronavirus disease discovered in 2019 or COVID-19 for short [2].

COVID-19 rapidly spread in china. This novel coronavirus is similar to SARS-CoV in their genetic information and it's termed as SARS-CoV-2 and has caused a large global outbreak [3].

The first case reported was close contact with animals in seafood market that may transmit from animal to human, then it was transmitted from human to human [2].

The transmission of SARS-CoV-2 is through droplets or direct contact and the possibility of transmission by asymptomatic carrier. Due to the tenacity of the virus, it is possible that a person can acquire COVID-19 by touching a contaminated surface or object, and then touching his or herown mouth, nose, or eyes [3].

In February 11, 2020, the Chinese center of Disease Control and Prevention published 72,314 cases of COVID-19 [4].

Multiple skin manifestations have been described in patients with confirmed or suspected COVID-19 infection. These include a morbilliform rash; urticaria; pernio-like acral lesions; livedo-like vascular lesions; and vesicular varicella-like eruptions. A severe multisystem inflammatory syndrome with mucocutaneous, systemic, laboratory, and imaging findings of atypical severe Kawasaki disease has also been reported in children and adolescents with COVID-19 [5].

\section{Differentional Diagnosis:}

1- Perniosis and Pseudo-Chilblains (“COVID toes") clinically presents as erythematous to violaceous papules over acral surfaces (usually the fingers and toes, less commonly the nose and ears) following exposure to cold (fittingly called "acrocyanosis"). Blistering, crusting, and ulceration can occur in severe cases [6].
2- Morbilliform Eruptions and Macular Erythema presented with pinkred macules and papules (morbilliform means "measles"-like) that most often arise on the trunk and then spread to extremities symmetrically [7].

3-Urticaria present as edematous, erythematous papules or plaques often with central pallor [8].

4- Vasculopathies, Livedo presented with livedo refers to a vascular reaction pattern that manifests as "mottling" of the skin, manifesting as a net-like/ reticular discoloration of the skin on the trunk and extremities [9].

5-Vesicular Eruptions present with either diffuse or localize vesicles refer to small fluid-filled skin lesions $(<1 \mathrm{~cm})$. Lesions larger than $1 \mathrm{~cm}$ are referred to as bullae [10].

\section{References}

1. Song Z, Xu Y, Bao L, Zhang L, Yu P, Qu Y. (2019) From SARS to MERS, Thrusting Coronaviruses into the Spotlight. Viruses. 11(1): 59.

2. Hoffmann M, Kleine-Weber H, Schroeder S, Kruger N, Herrler T, Erichsen S. (2020) SARS-CoV-2 Cell Entry Depends on ACE2 and TMPRSS2 and Is Blocked by a Clinically Proven Protease Inhibitor. Cell. 181(2): 271-280.

3. Zhu GD, Cao J. (2020) Challenges and countermeasures on Chinese malaria elimination programme during the coronavirus disease 2019 (COVID-19) outbreak. Zhongguo xue xi chong bing fang zhi za zhi. 32(1): 7-9.

4. Wu Z, McGoogan JM. Characteristics of and Important Lessons From the Coronavirus Disease 2019 (COVID-19) Outbreak in China: Summary of a Report of 72314 Cases From the Chinese Center for Disease Control and Prevention. JAMA.

5. Recalcati S, Barbagallo T, Frasin LA. Acral cutaneous lesions in the time of COVID-19. J Eur Acad Dermatol Venereo.

6. De Masson A, Bouaziz JD, Sulimovic L, Cassius C, Jachiet $\mathrm{M}$, Lonescu MA, Chilblains are a common cutaneous finding during the COVID-19 pandemic: a retrospective nationwide study from France. J Am Acad Dermatol.

7. Najarian DJ. (2020) Morbilliform Exanthem Associated with COVID-19. JAAD Case Rep. 6(6): 493-494.

8. Quintana-Castanedo L, Feito-Rodríguez M, Valero-López I, Chiloeches-Fernández C, Sendagorta-Cudós E, HerranzPinto P. (2020) Urticarial exanthem as early diagnostic clue for COVID-19 infection. JAAD Case Rep. 6(6): 498-499.

9. Fernandez-Nieto D, Jimenez-Cauhe J, Suarez-Valle A, Moreno-Arrones OM, Saceda-Corralo D, Arana-Raja A. (2020) Characterization of acute acro-ischemic lesions in non-hospitalized patients: a case series of 132 patients during the COVID-19 outbreak. J Am Acad Dermatol. 83(1): 61-63.

10. Fernandez-Nieto D, Ortega-Quijano D, Jimenez-Cauhe J, Burgos-Blasco P, de Perosanz-Lobo D, Suarez-Valle A, Clinical and histological characterization of vesicular COVID-19 rashes: A prospective study in a tertiary care hospital. Clin Exp Dermatol. 